\title{
The man they love to hate
}

\section{Bjørn Lomborg is reviled by green} activists and has come under ferocious attack from many environmental scientists. Just why does he provoke such strong reactions, and how influential might his opinions become? Jim Giles investigates.

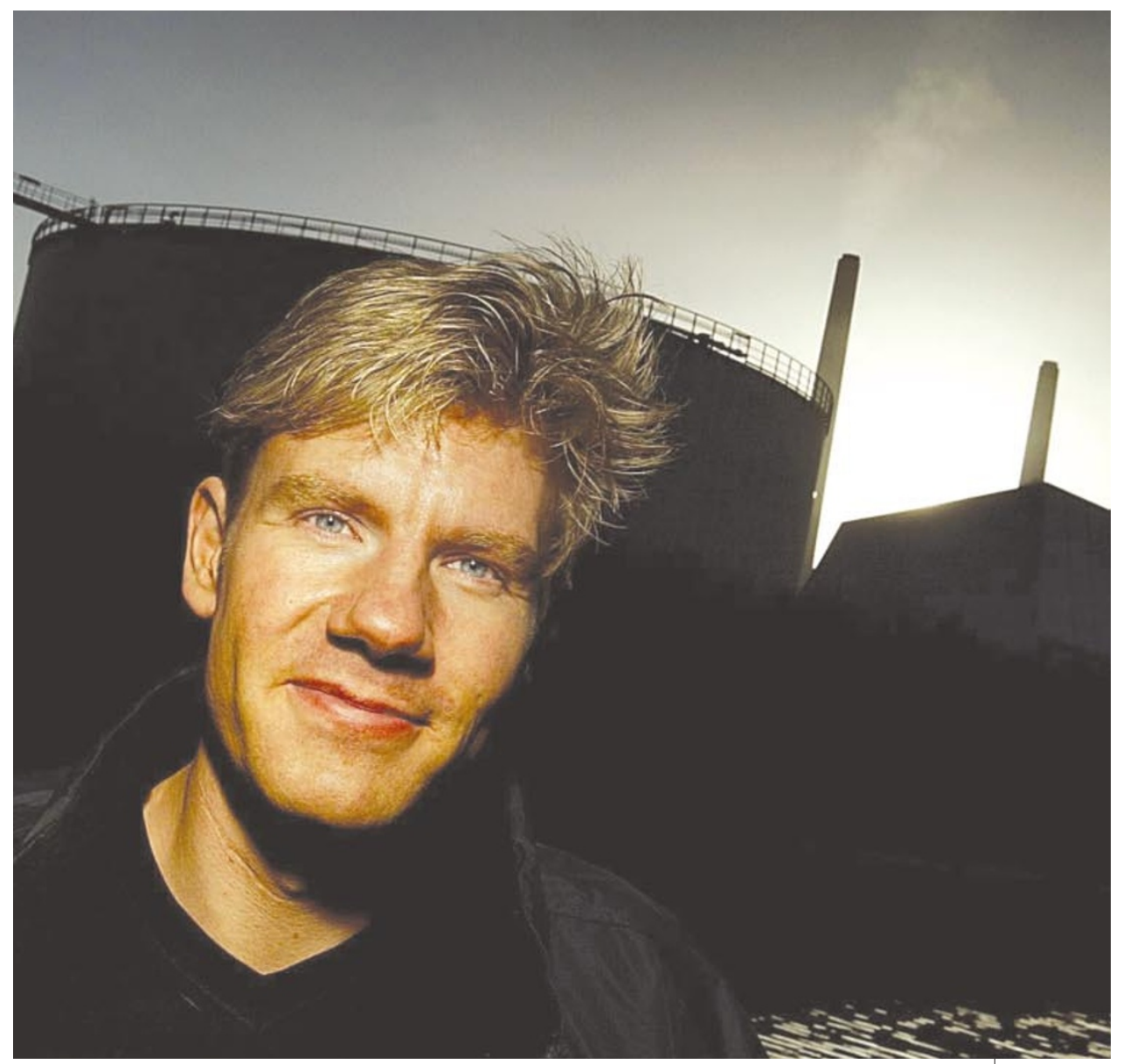

debate about environmental science?

The roots of The Skeptical Environmentalist lie in the work of another man whom the greens love to hate: the late free-market economist Julian Simon of the University of Maryland at College Park. In 1997, Lomborg, then a lecturer applying statistics to problems in political science at the University of Aarhus in Denmark, came across a magazine article in which Simon rebutted many of the doomsday predictions that environmentalists have made about the planet. "When I read the article I thought 'hell, no," Lomborg recalls. "I thought that obviously the environment is getting worse. But Simon said one irritating thing: go check the facts."

\section{Challenging task}

Lomborg formed a study group among his students to take up Simon's challenge. Describing himself as having a left-wing frame of mind, Lomborg says he assumed that it would be easy to debunk Simon's views as merely the product of conservative American thinking. "We all thought it would just be a matter of how much fun we would have showing he was wrong," he says. But Lomborg says the study group ended up agreeing with many of Simon's claims. Excited by what he was finding, Lomborg persuaded Politiken, a left-leaning Danish daily newspaper, to publish four essays summarizing his findings. Those essays evolved into a book that was released in Denmark in 1998 and eventually published in English by Cambridge University Press as The Skeptical Environmentalist.

Lomborg's approach was to use a mass of statistics on issues from species extinction to air pollution, taken from authoritative sources such as United Nations agencies, to gauge the state of the global environment. He concluded that things are not as bad as environmentalists have led us to believe. And although he was careful to say that we must continue to work to protect our environment, he also raised questions about whether current initiatives, such as the Kyoto Protocol on climate change, are the most cost-effective way to do so.

This call of 'crisis, what crisis?' resonated with elements of the conservative media: favourable reviews soon appeared in The Economist, The Wall Street Journal and British newspaper The Daily Telegraph. Not surprisingly, the environmental movement reacted with outrage. The World Resources Institute, an environmental research and policy group based in Washington DC, published a list of "Nine things journalists should know about The Skeptical Environmentalist" - arguing, among other things, that Lomborg was selective in the studies that he cited, and lacked the credentials to carry out his analysis correctly. 


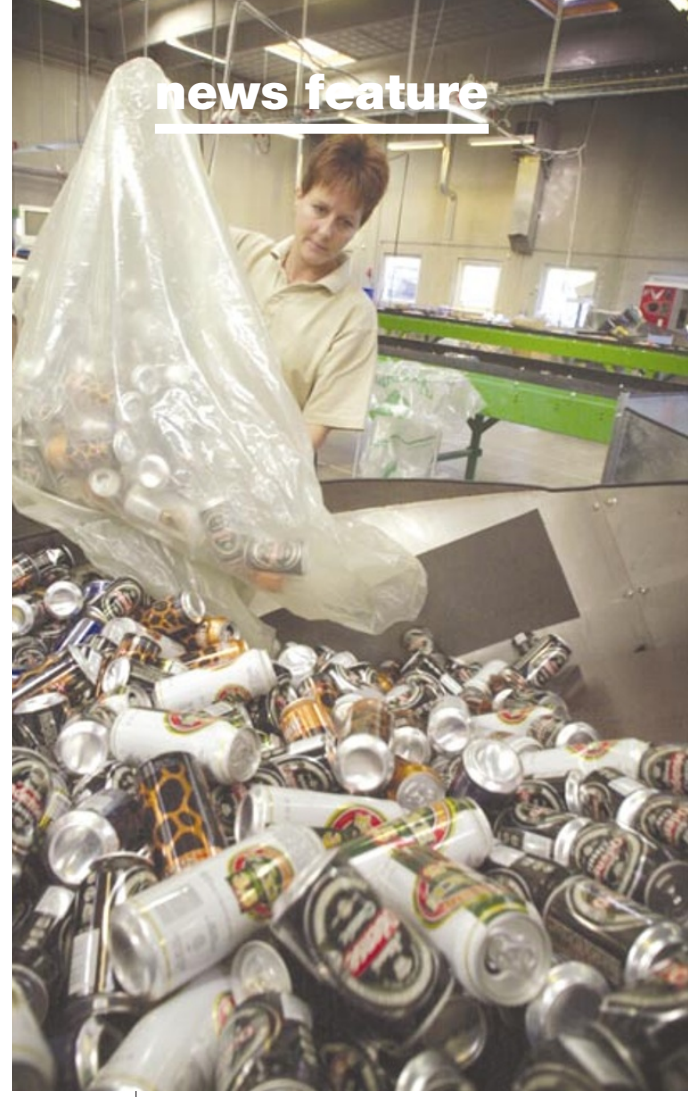

Trash cans: Lomborg's institute has questioned Denmark's devotion to aluminium recycling.

Some of Lomborg's opponents would dearly love to be able to portray him as a stooge of the political right. But that won't be easy. He seems entirely genuine about his stated position of having formed his views simply through unbiased statistical analysis. "I believe I have looked at the important indicators," says Lomborg. "If I sat down with dispassionate researchers, most of the time we would come up with conclusions that are close to mine."

Lomborg does, however, acknowledge that his position has provided succour for polluting industries, and for right-wing groups that are opposed to environmental legislation. "I know people use me for their political ends," he says. And he has been criticized for his decision in October 2001 to speak to members of the US Congress at a briefing organized by the Cooler Heads Coalition, a Washington DC-based group that campaigns against the Kyoto Protocol. Lomborg argues that his message is the same, whatever the circumstances. "I say the same things at oil-company meetings and ecology meetings. If researchers refrain from saying things that could be used politically, then they start acting as politicians," he says. Nevertheless, he has turned down some offers, including one from a plastics-industry organization that wanted to sponsor a lecture tour of the United States.

So what, in the long term, will be Lomborg's influence on the debate about the state of the planet? In Denmark, at least, he is continuing to make waves through his role as director of the country's Environmental Assessment Institute, which was established in January 2002 by the country's newly elected centre-right government. With 17 researchers and an annual budget of US $\$ 2$ million, its primary aim is to conduct cost-benefit analyses of environmental issues that are important to Denmark.

The institute has, for example, already challenged environmental advocates by questioning whether the money invested in recycling aluminium cans is well spent, and is now working on issues such as soil pollution and waste incineration.

More generally, few would argue that Lomborg's book has won over many hearts and minds. The Bush administration's policies on Kyoto and other environmental issues were largely formed before the book was published, and green activists continue to campaign using the same arguments as before. But some experts argue that the affair contains valuable lessons for environmental scientists: specifically, they argue that it shows how counterproductive it can be to respond to misleading claims with anything other than reasoned scientific argument. The tone of the scientists' attacks on Lomborg was often emotive, and they were sometimes seen as political. "I've yet to see a peer-reviewed response to Lomborg," points out Roger Pielke, an expert on science and technology policy at the University of Colorado at Boulder.

Pimm and Harvey's Nature book review, for instance, contains the following statement: "The text employs the strategy of those who, for example, argue that gay men aren't dying of AIDS, that Jews weren't singled out by the Nazis for extermination, and so on." And the series of critiques in Scientific American is subtitled: "Science defends itself against The Skeptical Environmentalist", as if science itself was under attack.

\section{Gripe hype}

Presenting Lomborg as an enemy of science may indeed have been hyperbole, and it certainly seemed to boost his profile. Chris Harrison, publishing director for social science at Cambridge University Press, who handled the book, says that sales quadrupled in the month following the appearance of the Scientific American articles - although he stresses that stirring up controversy was not a deliberate marketing strategy.

Perhaps the most surprising development in the affair was the move by a group of scientists, including Harvey, to report Lomborg to the Danish Committees on Scientific Dishonesty, an official body that is responsible for examining accusations of scientific misconduct.Even more surprising, to some observers, was the committees' decision to investigate. In a highly confusing judgement released in January, the committees' deemed The Skeptical Environmentalist "to fall within the concept of scientific dishonesty", because of its allegedly biased presentation of data, although the report conceded that there was no evidence that Lomborg had actually intended to deceive his readers (see Nature 421, 195 \& 201;2003).

The investigation has been heavily criticised for relying on published critiques of the book, in particular the Scientific American articles. Lomborg issued a lengthy rebuttal on his website and lodged complaints about the investigation with the Danish parliamentary ombudsman and the government. "He never, ever said anything but what he believed the data showed," says Kenneth Thue Nielsen, a member of Lomborg's original study group who was until recently a researcher at the Environmental Assessment Institute.

Nevertheless, Lomborg loses a little of his calm when discussing the investigation - it is evidently one of the few events over a turbulent couple of years that have really rattled him. "They simply said that if the four critical scientists in Scientific American said I was an idiot, then I must be," he complains. Fearing that the publicity surrounding the ruling was damaging the Environmental Assessment Institute's standing, its board of governors launched an independent review of all of the reports it has produced. Board members hope that the review, which should be ready in August, will provide a vote of confidence.

The real loser from the incident may, however, be the Danish Committees on Scientific Dishonesty, which now faces a review of its remit by the Danish government. And the committees' report definitely served to propel Lomborg and his controversial ideas back into the headlines at a time when interest had at last begun to wane. Whereas some news articles simply said that Lomborg had been found guilty of misconduct, others portrayed him as the victim of a witch-hunt.

Harvey has taken part in public debates with Lomborg on several occasions, and his opinions on the book have not changed. But looking back, he acknowledges that the venom with which Lomborg was attacked may have been counterproductive. "The affair has taught me to be more calm and measured," says Harvey. "We should have let the empirical evidence undermine Lomborg."

Harvey's comment illustrates an important lesson to be learned from the affair. The Skeptical Environmentalist is packed with facts and figures, yet it was the emotional response that it inspired that will be best remembered. The whole controversy, Pielke laments, is now perceived to have been about politics rather than science, and everyone has been tarred with the same brush: "Scientists are seen as the same as everyone else."

Jim Giles is Nature's associate news and features editor. Additional reporting by Nature intern Hannah Hoag.

Lomborg's website

1 www.lomborg.com

Anti-Lomborg

i www.mylinkspage.com/lomborg.html

Danish Environmental Assessment Institute

www.imv.dk 